Supporting Information for

\title{
Surface Modification and Functionalization of Nanoscale Metal-Organic Frameworks for Controlled Release and Luminescence Sensing
}

\author{
William J. Rieter, Kathryn M. L. Taylor, and Wenbin Lin* \\ Department of Chemistry, University of North Carolina, Chapel Hill, NC \\ 27599,wlin@unc.edu
}

1. Materials and Methods. Cetyltrimethylammonium bromide (CTAB), $\mathrm{GdCl}_{3}{ }^{\bullet} 6 \mathrm{H}_{2} \mathrm{O}$, $\mathrm{EuCl}_{3}{ }^{\circ} 6 \mathrm{H}_{2} \mathrm{O}$, terephthalic acid (BDC), 1-hexanol, methylamine (40 wt \% in water), polyvinylpyrrolidone (MW 40k), dipicolinic acid (DPA), 2,2,4-trimethylpentane, and TEOS were purchased from Aldrich and used without further purification. Ethanol, nitric acid, and aqueous ammonia were purchased from Fisher. The methylammonium salt of the BDC ligand was prepared by dissolving the ligands in minimal methylamine ( $40 \mathrm{wt}$ $\%$ in water), removing the solvent completely under reduced pressure at $60{ }^{\circ} \mathrm{C}$, and subsequently redissolving the solid salt in a known volume of distlilled water to reach the desired solution concentration. Thermogravimetric analysis (TGA) was performed using a Shimadzu TGA-50 equipped with a platinum pan and heated at a rate of $3{ }^{\circ} \mathrm{C} / \mathrm{min}$ under air. Powder X-ray diffraction (PXRD) patterns were collected on a Bruker SMART APEX II diffractometer using $\mathrm{Cu}$ radiation. The PXRD patterns were processed with the APEX 2 package using phase ID plugin. A JEM 100CX-II transmission electron microscope was used to determine particle size, morphology, and silica shell thickness. TEM samples were prepared from ethanolic particle dispersions on amorphous carbon coated copper grids. $\mathrm{Gd}^{3+}$ ion concentrations were measured on an Applied Research Laboratories (ARL) SpectraSpan 7 Direct Current Plasma (DCP) Spectrometer. Luminescence data were collected on a Shimadzu RF-5301PC Spectrofluorophotometer.

\section{Synthesis and Characterization of $\mathrm{Gd}(\mathrm{BDC})_{1.5}\left(\mathrm{H}_{2} \mathrm{O}\right)_{2} @ P V P(2)$.}

$\mathrm{Gd}(\mathrm{BDC})_{1.5}\left(\mathrm{H}_{2} \mathrm{O}\right)_{2}$ nanorods (1) were prepared via the cationic cetyltrimethylammonium bromide $(\mathrm{CTAB}) /$ isooctane/1-hexanol/water microemulsion system. Initially, a round bottom flask was charged with $\mathrm{CTAB}$ and a particular volume of $0.50 \mathrm{M}$ 1-hexanol in isooctane solution to obtain a milky white mixture with a CTAB concentration of $0.05 \mathrm{M}$. 
An aliquot of an aqueous solution of one reactant was then added to the above mixture corresponding to a particular $W$ value (water to surfactant molar ratio) to yield a visibly clear isotropic microemulsion. A separate microemulsion was prepared with an equivalent volume of an aqueous solution of the other reactant. After stirring the separate microemulsions until visibly clear, they were combined and stirred for an additional $2 \mathrm{~h}$ before functionalization with polyvinylpyrrolidone (PVP) or isolation via centrifugation.

As an example for the $W=15$ system, a microemulsion was prepared by adding 450 $\mu \mathrm{L}$ of a $0.15 \mathrm{M} \mathrm{GdCl}_{3}$ aqueous solution to $100 \mathrm{~mL} 0.05 \mathrm{M} \mathrm{CTAB} / 0.50 \mathrm{M} \mathrm{1-}$ hexanol/isooctane mixture followed by the addition of $900 \mu \mathrm{L}$ of distilled $\mathrm{H}_{2} \mathrm{O}$. Another microemulsion was prepared by adding $450 \mu \mathrm{L}$ of a $0.20 \mathrm{M}$ di(methylammonium)benzenedicarboxylate solution to $100 \mathrm{~mL} 0.05 \mathrm{M} \mathrm{CTAB} / 0.50 \mathrm{M}$ 1-hexanol/isooctane mixture followed by the addition of $900 \mu \mathrm{L}$ of distilled $\mathrm{H}_{2} \mathrm{O}$. Both microemulsions were then stirred vigorously for at least $10 \mathrm{~min}$ at room temperature, or until optically transparent, after which they were combined and the resultant microemulsion was stirred for an additional $2 \mathrm{~h}$ before adding $1.35 \mathrm{~mL}$ of a $0.005 \mathrm{M}$ polyvinylpyrrolidone (PVP, $\mathrm{MW}=40 \mathrm{k}$ ) solution. After stirring the reaction mixture for an additional $12 \mathrm{~h}$ at room temperature the PVP functionalized nanoparticles were isolated via centrifugation at $10,000 \mathrm{rpm}$ for $15 \mathrm{~min}$, washed with ethanol, and subsequently re-dispersed in ethanol via sonication. An aliquot of the above dispersion was evaporated to dryness for powder X-ray diffraction (PXRD) and thermogravimetric analysis (TGA). A quantitative yield was obtained based on the expected formula mass.

\section{Synthesis and Characterization of $\mathrm{Ln}(\mathrm{BDC})_{1.5}\left(\mathrm{H}_{2} \mathrm{O}\right)_{2} @ \mathrm{SiO}_{2}$ core-shell} nanoparticles (3). Nanoparticles of 3 were prepared using well-established sol-gel techniques. An aliquot of 2 in ethanol was diluted to a volume corresponding to $5 \mathrm{~mL}$ ethanol/mg of 2 with absolute ethanol. To this dispersion was added an aliquot of aqueous $\mathrm{NH}_{4} \mathrm{OH}$ to obtain $4 \%$ (v/v) $\mathrm{NH}_{3}$ in ethanol. With magnetic stirring, tetraethyl orthosilicate (TEOS, $5 \mu \mathrm{L} / 1 \mathrm{mg}$ of 2 synthesized at $W<10$ and 1.25 to $2.5 \mu \mathrm{L} / 1 \mathrm{mg}$ of 2 synthesized at $W>10$ ) was added to the dispersion and the reaction was continued for at least 2 hours. Silica shell thickness would typically increase with reaction time and volume of TEOS added to the reaction mixture. 
More specifically, for an approximately $3 \mathrm{~nm}$ thick silica shell on nanoparticles of $\mathbf{2}$ synthesized at $W=5,11.2 \mathrm{mg}$ of 2 was dispersed in $60 \mathrm{~mL}$ of $4 \% \mathrm{NH}_{3}$ in ethanol. $56 \mu \mathrm{L}$ of TEOS was added to the dispersion with magnetic stirring at room temperature. After 2 $\mathrm{h}$, another $56 \mu \mathrm{L}$ of TEOS was added and the reaction was continued for $3 \mathrm{~h}$. Nanoparticles of 2 were isolated by centrifuging at $13000 \mathrm{rpm}$ for $10 \mathrm{~min}$, washed with ethanol, and re-dispersed in the desired solvent via sonication. A thick shell with minimal secondary nucleation was obtained simply by increasing the reaction time for the second step from $3 \mathrm{~h}$ to $7 \mathrm{~h}$.

For a thin amorphous, discontinuous silica shell on nanoparticles of $\mathbf{2}$ synthesized at $W=15,20.0 \mathrm{mg}$ of 2 was dispersed in $100 \mathrm{~mL} 4 \% \mathrm{NH}_{3}$ in ethanol. $25.0 \mu \mathrm{L}$ of TEOS was added to the dispersion with magnetic stirring. After $2 \mathrm{~h}, 100 \mu \mathrm{L}$ of TEOS was added and the reaction was continued for an additional $3 \mathrm{~h}$. Nanoparticles of 3 were then isolated by centrifugation, washed twice with EtOH, and redispersed in ethanol. An 8-9 $\mathrm{nm}$ silica shell for these high aspect ratio nanorods was obtained by reintroducing the isolated silica-primed NMOFs into a separate sol-gel reaction with a TEOS concentration of $5 \mu \mathrm{L} / 1 \mathrm{mg}$ of 3 , and stirring the resultant mixture for $6 \mathrm{~h}$ at room temperature. The nanoparticles were then isolated as described above.

4. Determination of Rate of Dissociation. Approximately $15 \mathrm{mg}$ of dry uncoated NMOFs were dialyzed against $500 \mathrm{~mL}$ of an aqueous solution with slow magnetic stirring at $37{ }^{\circ} \mathrm{C}$. The $\mathrm{pH}$ of the solution was adjusted prior to submerging the sample with dilute $\mathrm{HNO}_{3}$ and/or $\mathrm{NaOH}$. Aliquots of the solution were removed at predesignated times and the solvent was evaporated under reduced pressure. The sample was then diluted to $3 \mathrm{~mL}$ with $1 \mathrm{M} \mathrm{HNO}_{3}$ for DCP analysis. Initially, larger volumes were removed to increase the detection limits (up to $30 \mathrm{~mL}$ of the solution was taken to increase the Gd detection sensitivity by a factor of 10). For silica-coated NMOFs an amount of sample was added corresponding to $\sim 15 \mathrm{mg}$ of NMOF based on TGA (e.g. $\sim 22 \mathrm{mg}$ were added for NMOFs with an 8-9 $\mathrm{nm}$ coat synthesized at $W=15$ ).

\section{Synthesis of 3-aminopropyl(triethoxysilyl)ethylenediamine triacetic acid} monoamide (Si-EDTM). Ethylenediaminetetraacetic acid mono anhydride was first 
synthesized from the dianhydride, following a procedure published by Ebright et al. ${ }^{1}$ $1.000 \mathrm{~g}$ (3.903 mmol) of EDTA-dianhydride was dissolved in $5 \mathrm{~mL}$ of dry DMF by heating to $100^{\circ} \mathrm{C}$. After the EDTA-dianhydride had dissolved, the solution was cooled to $75^{\circ} \mathrm{C}$. $70 \mu \mathrm{L}(3.885 \mathrm{mmol})$ of $\mathrm{H}_{2} \mathrm{O}$ was then dissolved in $1 \mathrm{~mL}$ of dry DMF. This solution was then added to the dianhydride dropwise. After the addition was complete, the reaction was stirred for an additional 2 hours at $75^{\circ} \mathrm{C}$. The heat was then removed, and the reaction was stirred at room temperature, overnight to allow the product to precipitate. The product was then collected by filtration. Yield: $0.9259 \mathrm{~g}(86.5 \%) .{ }^{1} \mathrm{H}$ NMR (DMSO, $300 \mathrm{MHz}): \delta 3.71(\mathrm{~s}, 4 \mathrm{H}), \delta 3.42(\mathrm{~s}, 4 \mathrm{H}), \delta 2.79\left(\mathrm{t}, J_{\mathrm{H}-\mathrm{H}}=6.0 \mathrm{~Hz}, 2 \mathrm{H}\right), \delta$ $2.57\left(\mathrm{t}, J_{\mathrm{H}-\mathrm{H}}=6.0 \mathrm{~Hz}, 2 \mathrm{H}\right)$.

3-aminopropyl(triethoxysilyl)ethylenediamine triacetic acid was then synthesized by suspending $0.2500 \mathrm{~g}(0.9116 \mathrm{mmol})$ of EDTA-monoanhydride in $8 \mathrm{~mL}$ of anhydrous pyridine. $0.21 \mathrm{~mL}(0.20 \mathrm{~g}, 0.90 \mathrm{mmol})$ of 3-aminopropyltriethoxysilane was then added, and the reaction was stirred at room temperature under $\mathrm{N}_{2}$ for 16 hours. The product was precipitated upon the addition of hexanes, and collected by centrifuging at $3300 \mathrm{rpm}$. The product was then washed with additional hexanes, and dried under vacuum. Yield: $0.2528 \mathrm{~g}(56.0 \%) .{ }^{1} \mathrm{H}$ NMR (DMSO, $\left.400 \mathrm{MHz}\right): \delta 8.08(\mathrm{~s}, 1 \mathrm{H}), \delta 3.70$ (q, $J_{\mathrm{H}-\mathrm{H}}=7.5 \mathrm{~Hz}$, $12 \mathrm{H}), \delta 3.35$ (s, 4H), $\delta 3.19$ (s, 4H), $\delta 3.04$ (br., 4H), $\delta 2.69$ (s, 4H), $\delta 1.44(\mathrm{~m}, 4 \mathrm{H}), \delta$ $1.12\left(\mathrm{t}, J_{\mathrm{H}-\mathrm{H}}=7.0 \mathrm{~Hz}, 18 \mathrm{H}\right), \delta 0.51\left(\mathrm{t}, J_{\mathrm{H}-\mathrm{H}}=8.2 \mathrm{~Hz}, 2 \mathrm{H}\right)$.

Synthesis of Tb-Si-EDTM Complex. To prepare the terbium complex, Si-EDTA $(0.1000 \mathrm{~g}, 0.2018 \mathrm{mmol})$ was dissolved in $3 \mathrm{eq}$ of $\mathrm{NaOH}(1.21 \mathrm{~mL}$ of a $0.5 \mathrm{M}$ solution) at room temperature with magnetic stirring. One equivalent of $\mathrm{TbCl}_{3}(1.35 \mathrm{~mL}$ of a $0.15 \mathrm{M}$ solution) was then added dropwise, and the solution was stirred for an additional 30 minutes. Approximately $5 \mathrm{~mL}$ of ethanol was then added to the solution to precipitate the complex, which was isolated by centrifuging at $3200 \mathrm{rpm}$ for 10 minutes. The complex was then washed with additional ethanol and dried. Yield: $0.0555 \mathrm{~g}$ (39.0\%). The complex was dissolved in distilled water, and diluted to a total volume of $5 \mathrm{~mL}$ to give a $\sim 0.016 \mathrm{M}$ solution.

\section{Synthesis of Tb-EDTM terminated $\mathrm{Eu}_{0.02}: \mathrm{Gd}_{0.98}(\mathrm{BDC})_{1.5}\left(\mathrm{H}_{2} \mathrm{O}\right)_{2} @ \mathrm{SiO}_{2}$}

Nanoparticles. Eu-doped PVP-functionalized NMOFs were synthesized at $W=5$ and 
coated with an 8-9 nm silica shell as previously described. An aliquot of a stock suspension of the silica-coated NMOFs in ethanol was diluted to a total volume of $4 \mathrm{~mL}$ to give a particle concentration of $2.2 \mathrm{mg} / \mathrm{mL}$. The $\mathrm{pH}$ of the suspension was adjusted to approximately 10 by the addition of aqueous ammonia. $42 \mu \mathrm{L}$ of a $0.0176 \mathrm{M}$ solution of the Tb-Si-EDTA complex was then added, and the reaction was stirred at room temperature for 16 hours. The particles were then isolated by centrifuging at $12500 \mathrm{rpm}$ for 15 minutes, and were washed with distilled water and ethanol, before being redispersed in $2 \mathrm{~mL}$ of ethanol.

7. Luminescent Detection of Dipicolinic Acid. An aliquot (180 $\mu \mathrm{L})$ of the stock suspension of Tb-EDTM terminated $\mathrm{Eu}_{0.02}: \mathrm{Gd}_{0.98}(\mathrm{BDC})_{1.5}\left(\mathrm{H}_{2} \mathrm{O}\right)_{2} @ \mathrm{SiO}_{2}$ was diluted to a total volume of $2 \mathrm{~mL}$ with additional ethanol, to give a final particle concentration of 0.5 $\mathrm{mg} / \mathrm{mL}$. The suspension was then excited at $278 \mathrm{~nm}$, and the emission spectrum was recorded. An aqueous solution of dipicolinic acid (DPA) sodium salt was then added incrementally increasing the DPA concentration from $0.05 \mu \mathrm{M}$ to $200 \mu \mathrm{M}$. After each addition, the sample was excited at $278 \mathrm{~nm}$, and the emission spectrum was recorded. In addition, the intensity of each of the following peaks was measured 4 times, and the average was used to determine the intensity ratios: $544 \mathrm{~nm}, 592 \mathrm{~nm}$, and $615 \mathrm{~nm}$.

The DPA detection limit was estimated using the background intensity plus three standard deviations. A plot of the intensity ratio $(544 \mathrm{~nm} / 592 \mathrm{~nm})$ versus [DPA] from 0 to $0.6 \mu \mathrm{M}$ gives a linear fit with the equation: $\mathrm{y}=0.1501 \mathrm{x}+0.0436$. The background intensity ratio was measured to be $0.04426 \pm 0.00216$, so the background plus three standard deviations is equal to 0.05074. By plugging this value into the equation for the linear fit, a [DPA] of $47.6 \mathrm{nM}$ is determined to be the detection limit.

Luminescent Detection of DPA in a Buffer Solution. An aliquot $(8 \mu \mathrm{L})$ of a stock suspension of Tb-EDTM terminated $\mathrm{Eu}_{0.02}: \mathrm{Gd}_{0.98}(\mathrm{BDC})_{1.5}\left(\mathrm{H}_{2} \mathrm{O}\right)_{2} @ \mathrm{SiO}_{2}(21 \mathrm{mg} / \mathrm{mL}-\mathrm{a}$ different batch from the above) was added to $2 \mathrm{~mL}$ of a $10 \mathrm{mM}$ Tris buffered ethanol in water (1:1) solution at $\mathrm{pH} 7.6$. The suspension was then excited at $278 \mathrm{~nm}$, and the emission spectrum was recorded. An aqueous solution of DPA disodium salt was then added incrementally increasing the DPA concentration from $0.10 \mu \mathrm{M}$ to $200 \mu \mathrm{M}$. After each addition, the sample was excited at $278 \mathrm{~nm}$, and the emission spectrum was 
recorded. In addition, the intensity of each of the following peaks was measured 4 times, and the average was used to determine the intensity ratios: $544 \mathrm{~nm}, 592 \mathrm{~nm}$, and $615 \mathrm{~nm}$. A very similar dependence of Tb-DPA to Eu signal intensity ratio on DPA concentration was observed for 3'-Tb-EDTM in the buffered solution (Fig S16). The DPA detection limit was estimated to be $56.6 \mathrm{nM}$ in the buffered solution using the above method.

Luminescent Detection of DPA in the presence of $L$-Alanine. The luminescence experiment was similarly carried out in the presence of $0.6 \mathrm{mM} \mathrm{L}$-alanine, a biologically relevant carboxylic acid containing molecule, in a $10 \mathrm{mM}$ Tris buffered ethanol in water (1:1) solution at $\mathrm{pH}$ 7.6. The overlay of the curves for the titration of DPA into a buffered suspension with and without $L$-alanine showed that the relationship between curves for the same batch of 3'-Tb-EDTM nanorods correlated quite well with each other and the curves followed similar saturation behavior (Figure S16). These results showed that there was no interference from $L$-alanine.

To further determine if the Tb-EDTM complex was selective for the DPA ligand against other biologically relevant carboxylic acid containing molecules, $4 \mu \mathrm{L}$ of the nanoparticle stock suspension was added to $2 \mathrm{~mL}$ of the $10 \mathrm{mM}$ Tris buffered ethanol in water (1:1) solution at $\mathrm{pH}$ 7.6. To the suspension was added an aliquot of a DPA disodium salt aqueous solution to reach the desired DPA concentration. One sample was brought to a [DPA] of $5 \mu \mathrm{M}$ while another was brought to a [DPA] of $150 \mu \mathrm{M}$. The luminescence was allowed to reach equilibrium over several minutes, and was subsequently recorded. To the DPA nanoparticle suspensions were added aliquots of 100 $\mathrm{mM}$ Ala to achieve final Ala concentrations of $0.3,0.6,0.9$, and $1.2 \mathrm{mM}$. The luminescent intensities were recorded approximately 5 minutes after each addition and the ratio of $\mathrm{Tb}$ to Eu luminescent intensities were plotted against the [Ala] (Fig S17). There is a negligible change in the ratios of luminescent intensities even in the presence of over 200 fold excess of Ala. 


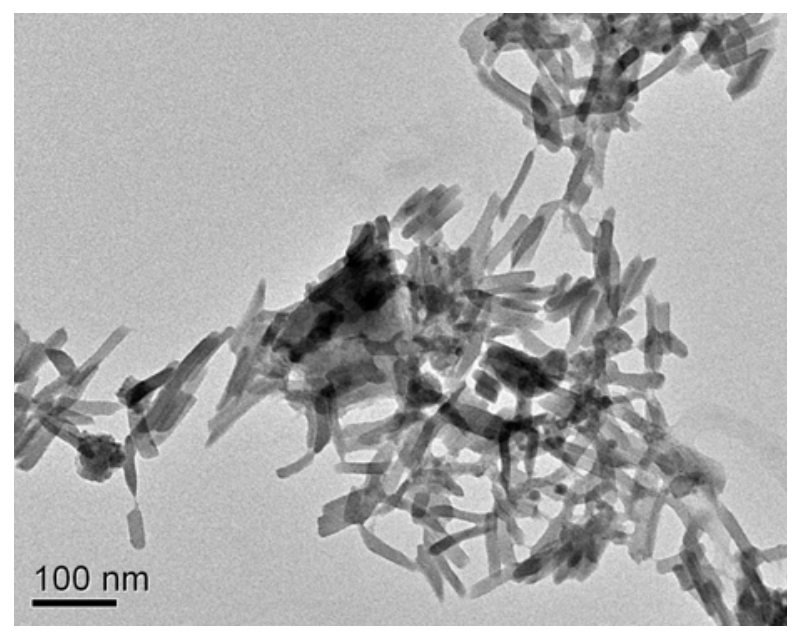

Figure S1. Representative TEM image of $\mathrm{Gd}(\mathrm{BDC})_{1.5}\left(\mathrm{H}_{2} \mathrm{O}\right)_{2}$ nanorods (1) synthesized at $W=5$, showing severe aggregation of the nanorods.

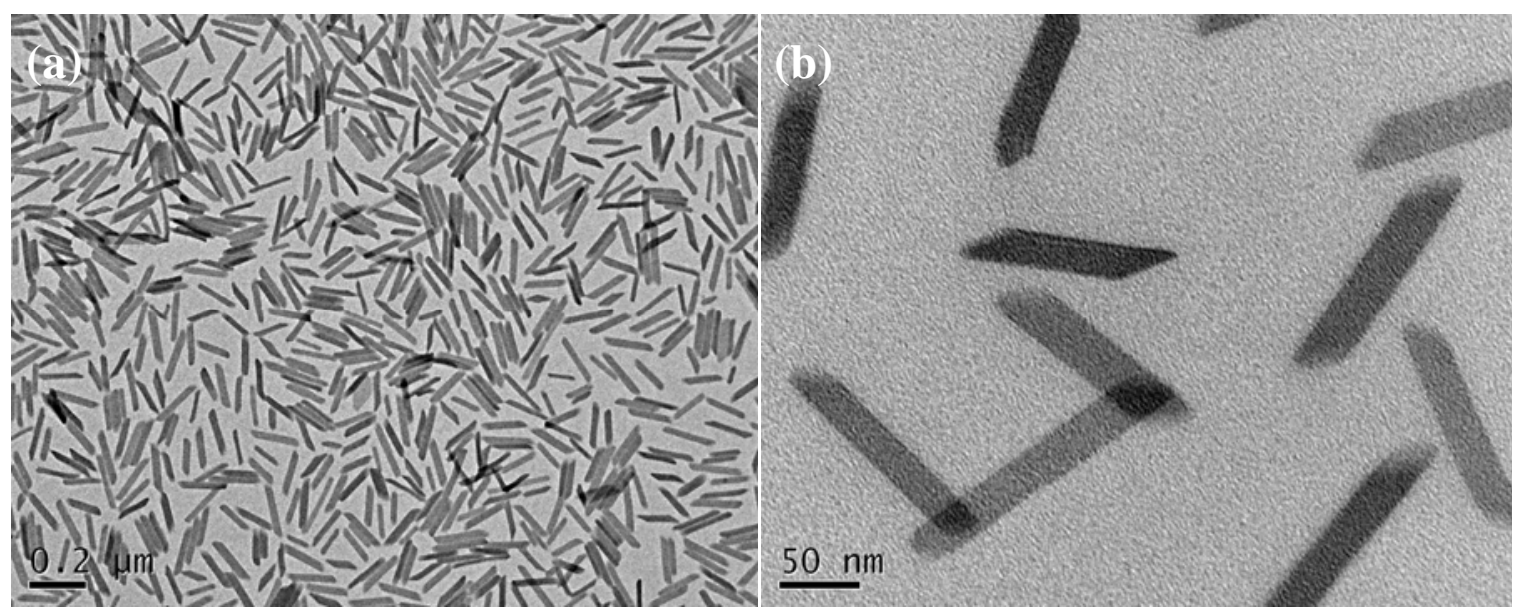

Figure S2. Representative TEM images of PVP-coated $\mathrm{Gd}(\mathrm{BDC})_{1.5}\left(\mathrm{H}_{2} \mathrm{O}\right)_{2}$ nanorods (2) synthesized at $W=5$. (a) Large area image; (b) high magnification image corresponding to Fig. $1 \mathrm{~b}$ in the paper. 


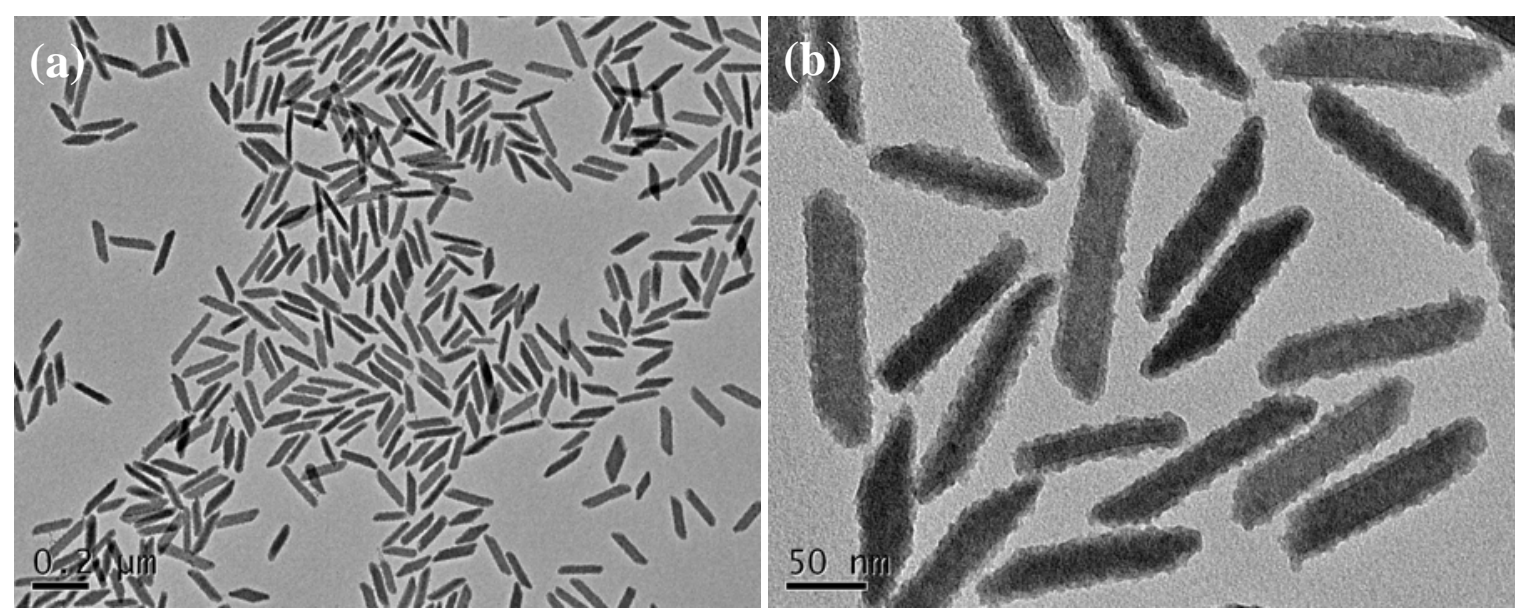

Figure S3. TEM images of 3 synthesized at $W=5$ with a 2-3 nm silica shell. (a) Large area image; (b) high magnification image corresponding to Fig. 1c in the paper.
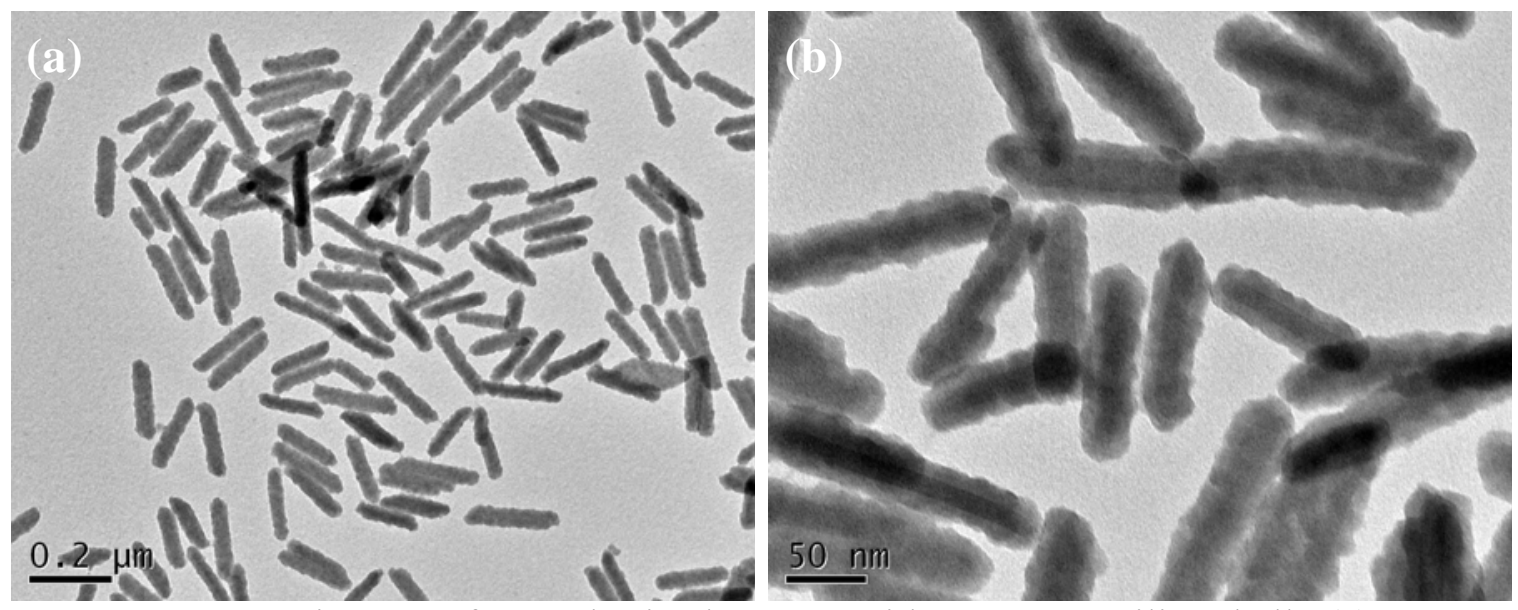

Figure S4. TEM images of 3 synthesized at $W=5$ with an $8-9 \mathrm{~nm}$ silica shell. (a) Large area image; (b) high magnification image corresponding to Fig. 1d in the paper.
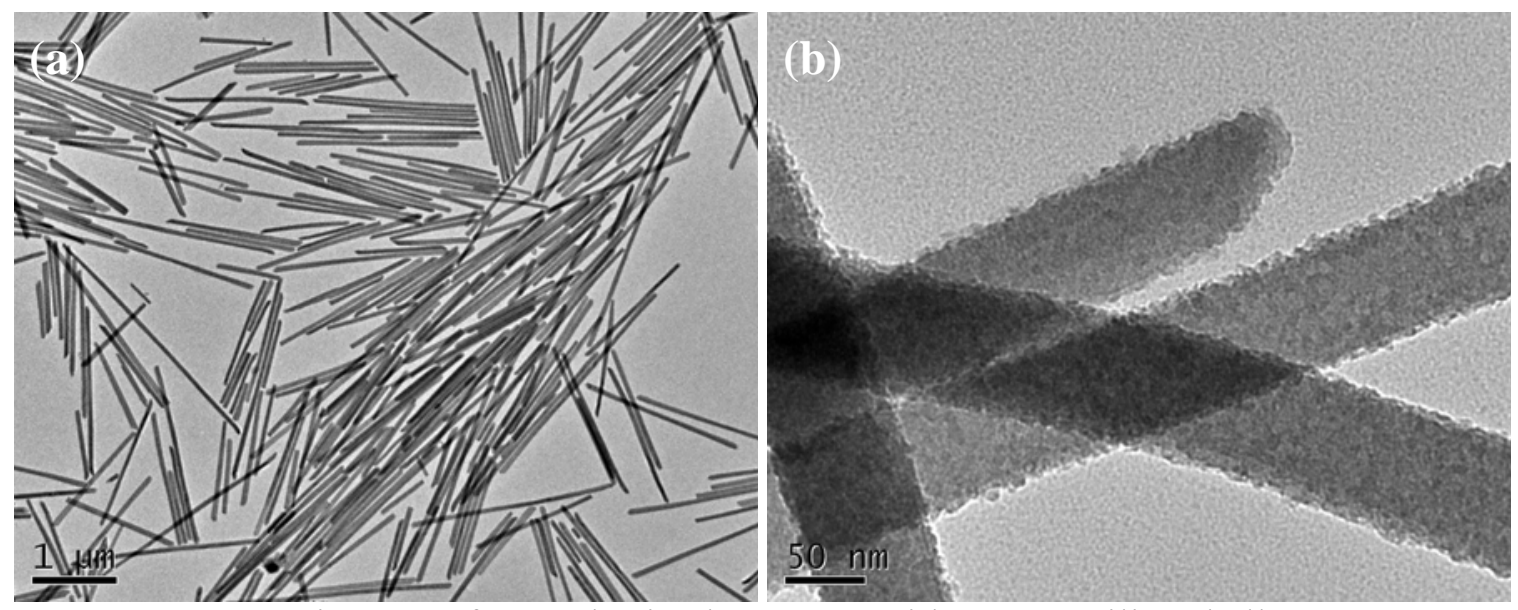

Figure S5. TEM images of 3 synthesized at $W=15$ with $2-3 \mathrm{~nm}$ silica shell. 

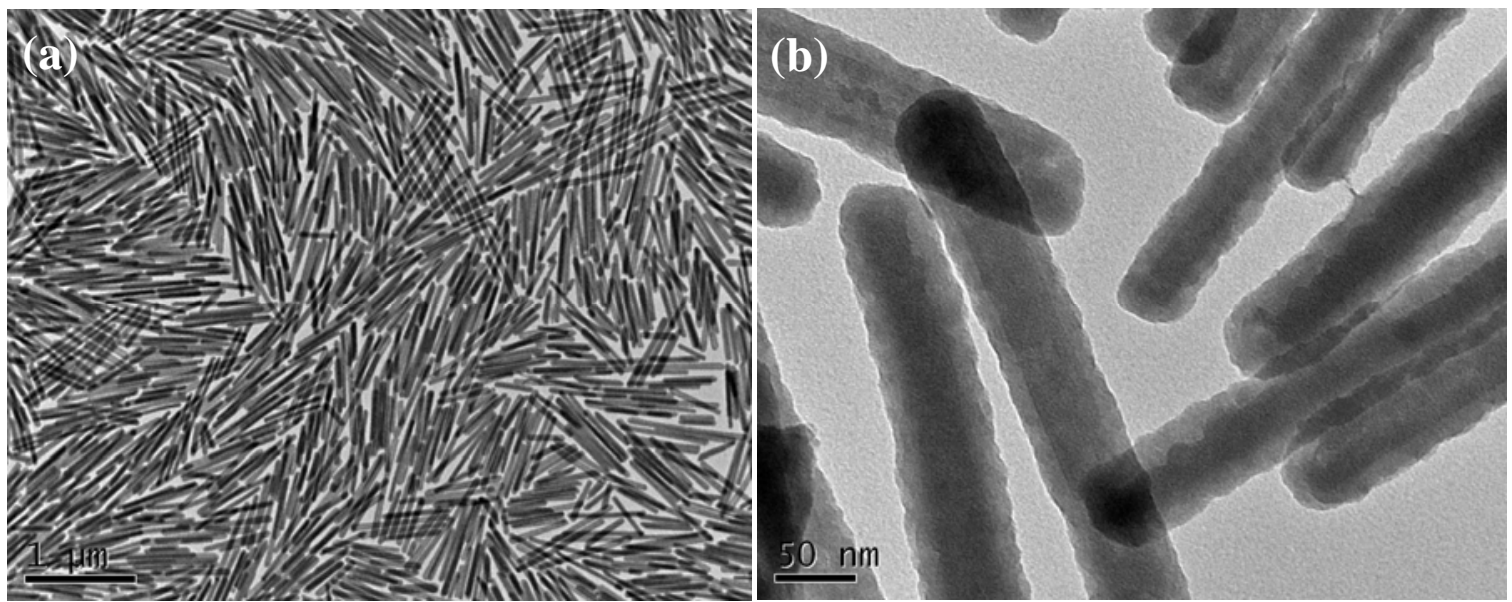

Figure S6. TEM images of 3 synthesized at $W=15$ with $\sim 8-9 \mathrm{~nm}$ silica shell. (a) Large area image; (b) high magnification image corresponding to Fig. $1 \mathrm{~g}$ in the paper.
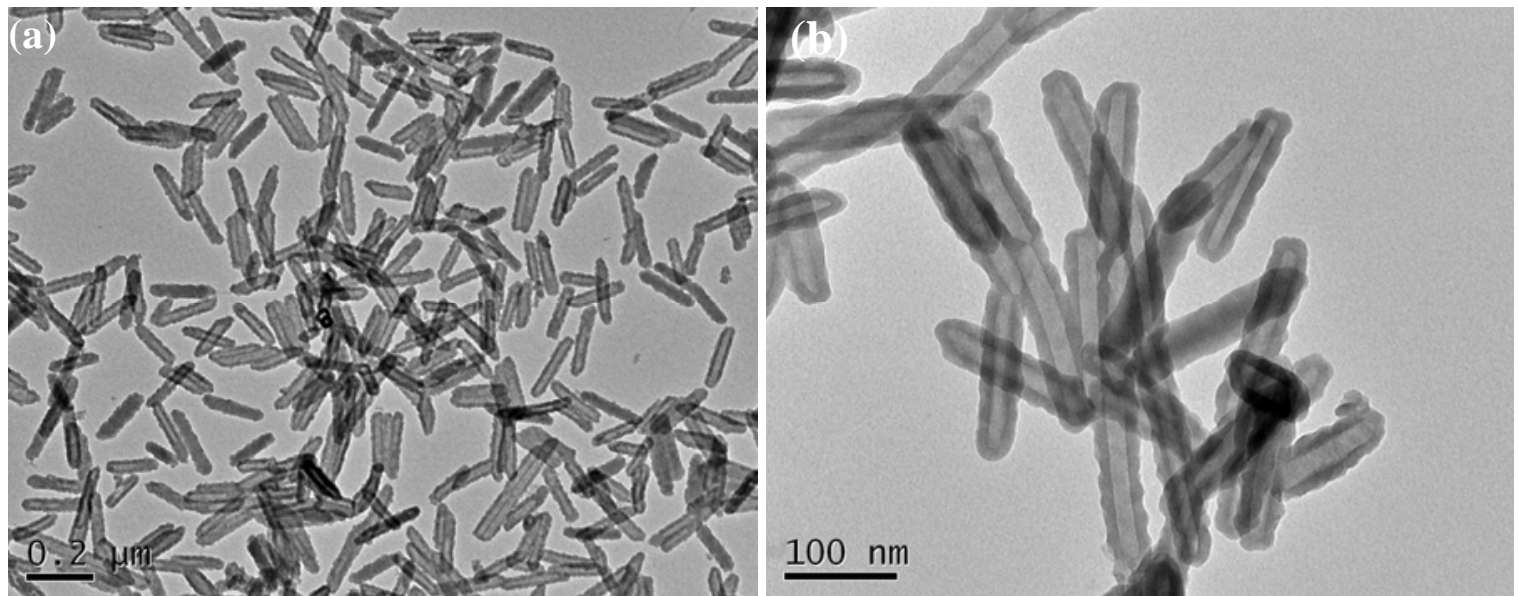

Figure S7. TEM images of hollow silica shell ( $8-9 \mathrm{~nm}$ in thickness) prepared from 3 synthesized at $W=5$.
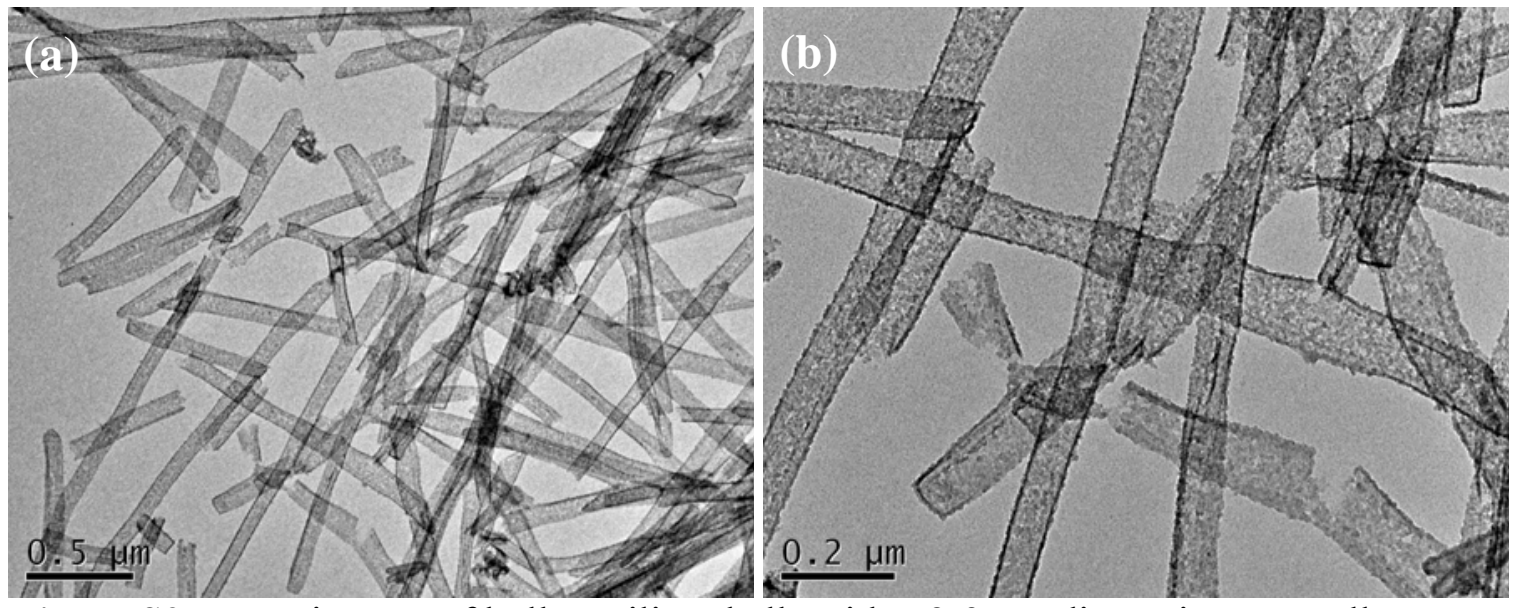

Figure S8. TEM images of hollow silica shells with a 2-3 nm discontinuous wall prepared from 3 synthesized at $W=15$. The nanoshells easily broke upon sonication. 

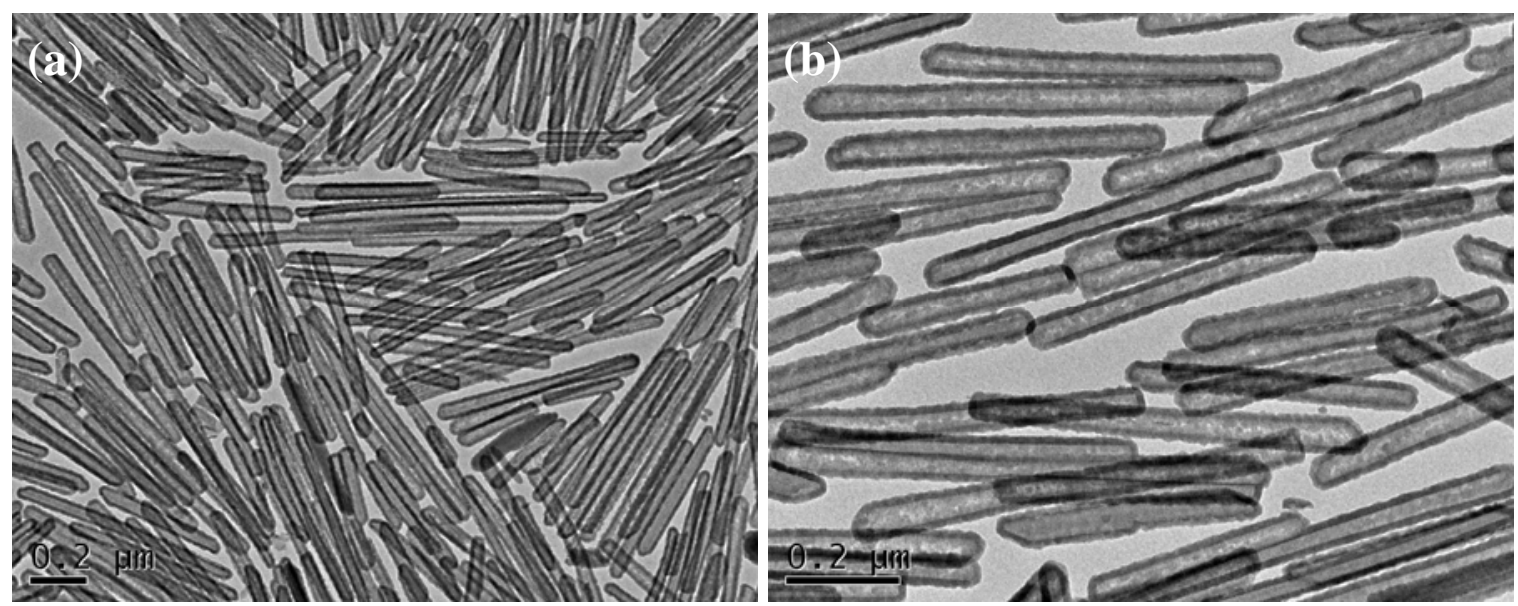

Figure S9. TEM images of hollow silica nanoshells (8-9 $\mathrm{nm}$ in thickness) prepared from nanoparticles of 3 synthesized at $W=15$.

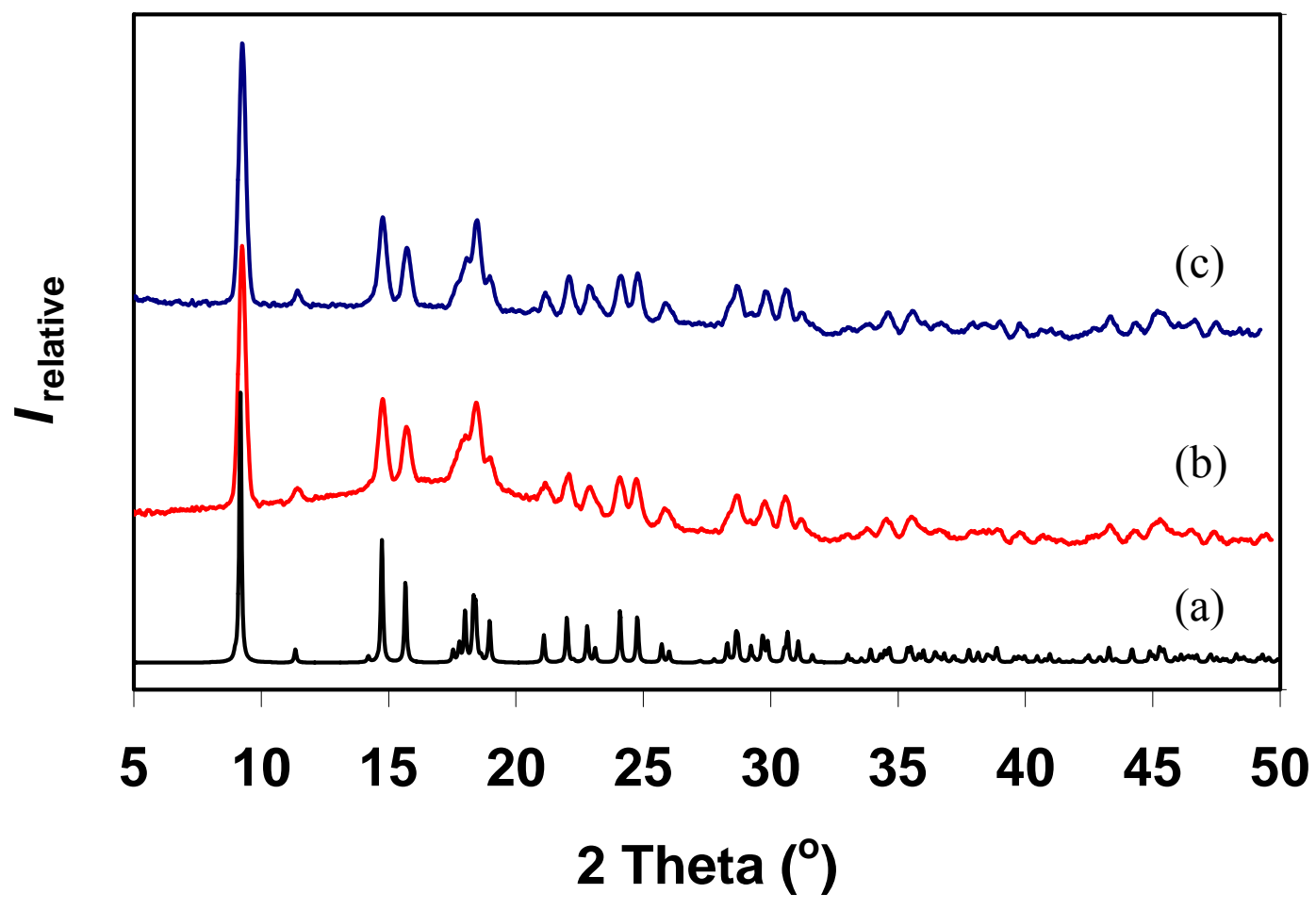

Figure S10. Powder XRD patterns for (a) the calculated crystal structure (b) nanoparticles of $\mathbf{2}$ and (c) nanoparticles of 3. 


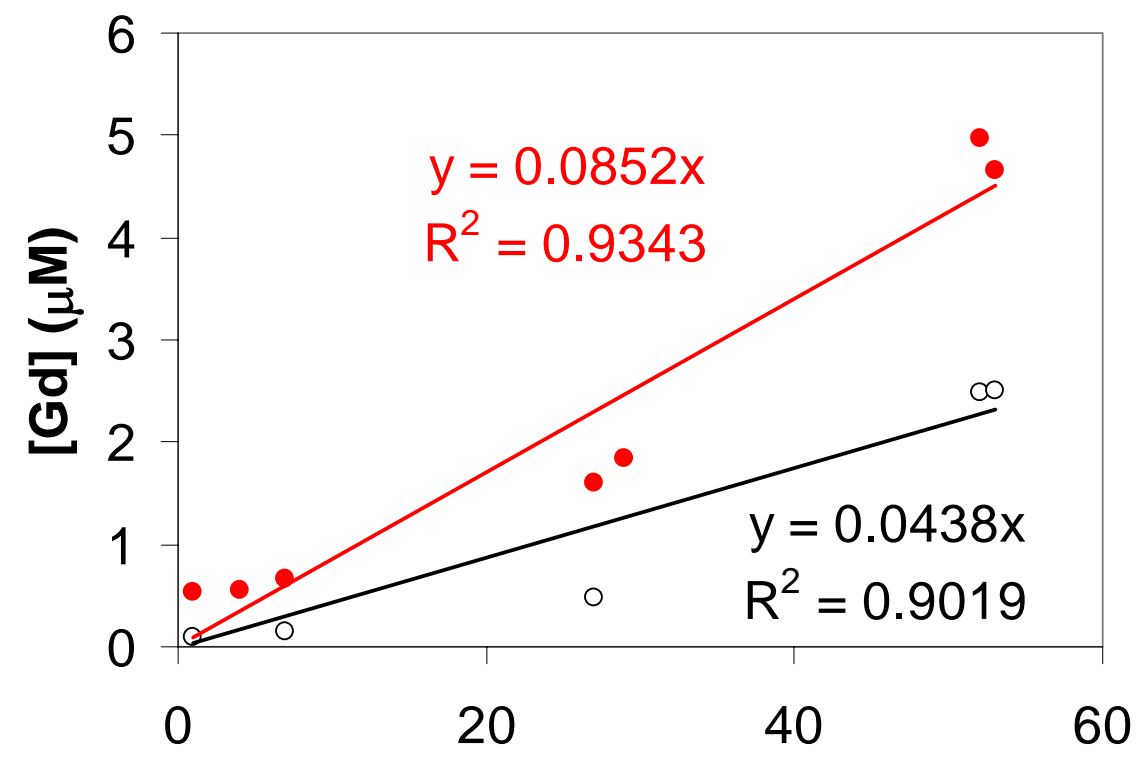

Figure S11. Time-dependent dissolution curves for 1 (red) and 3 with an 8-9 nm silica shell (black) at $\mathrm{pH}=5$ and $37^{\circ} \mathrm{C}$.

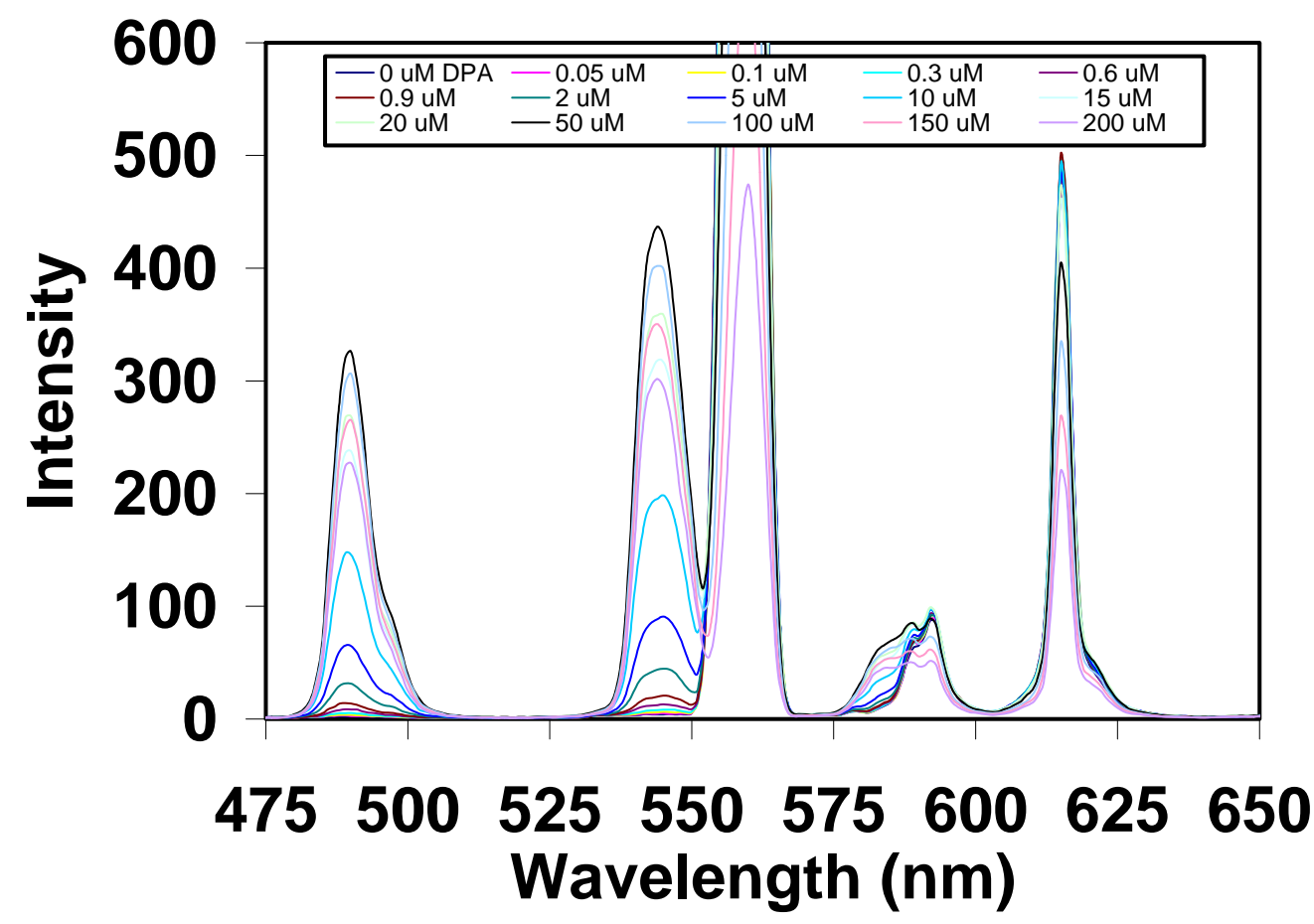

Figure S12. Luminescence vs. DPA concentration for for 3'-Tb-EDTM (with 0.2 monolayer of Tb-EDTM loading) $\left(\lambda_{\mathrm{ex}}=278 \mathrm{~nm}\right)$. 


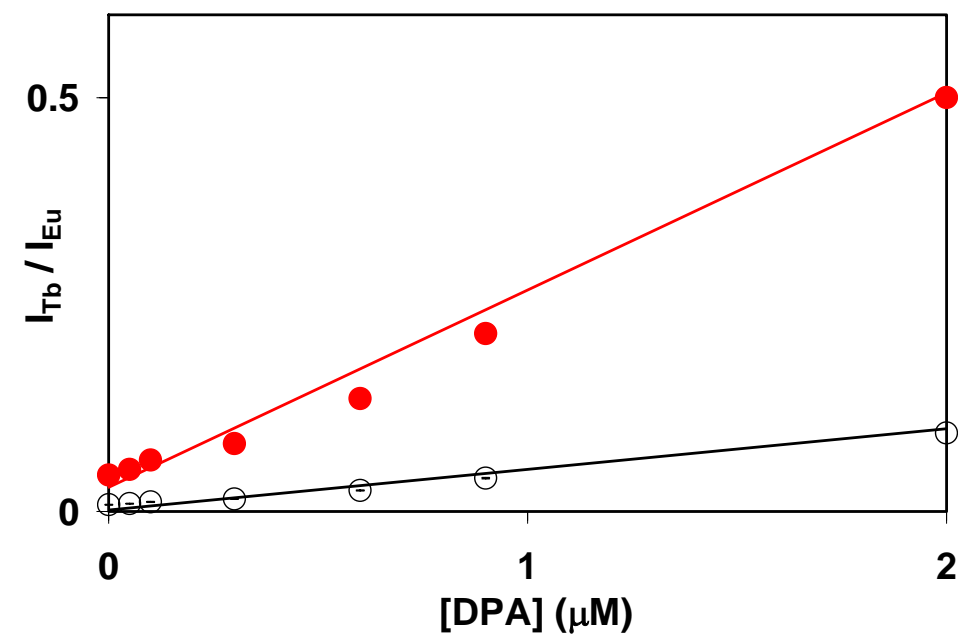

Figure S13. Ratio of Tb-DPA to Eu signal intensity vs. DPA concentration for $3^{\prime}-\mathrm{Tb}$ EDTM (with 0.2 monolayer of Tb-EDTM loading) at low DPA concentrations (red $=\mathrm{Tb}$ $\mathrm{DPA}_{544 \mathrm{~nm}}: \mathrm{Eu}_{592 \mathrm{~nm}} ;$ black $\left.=\mathrm{Tb}-\mathrm{DPA}_{544 \mathrm{~nm}}: \mathrm{Eu}_{615 \mathrm{~nm}}\right)$.

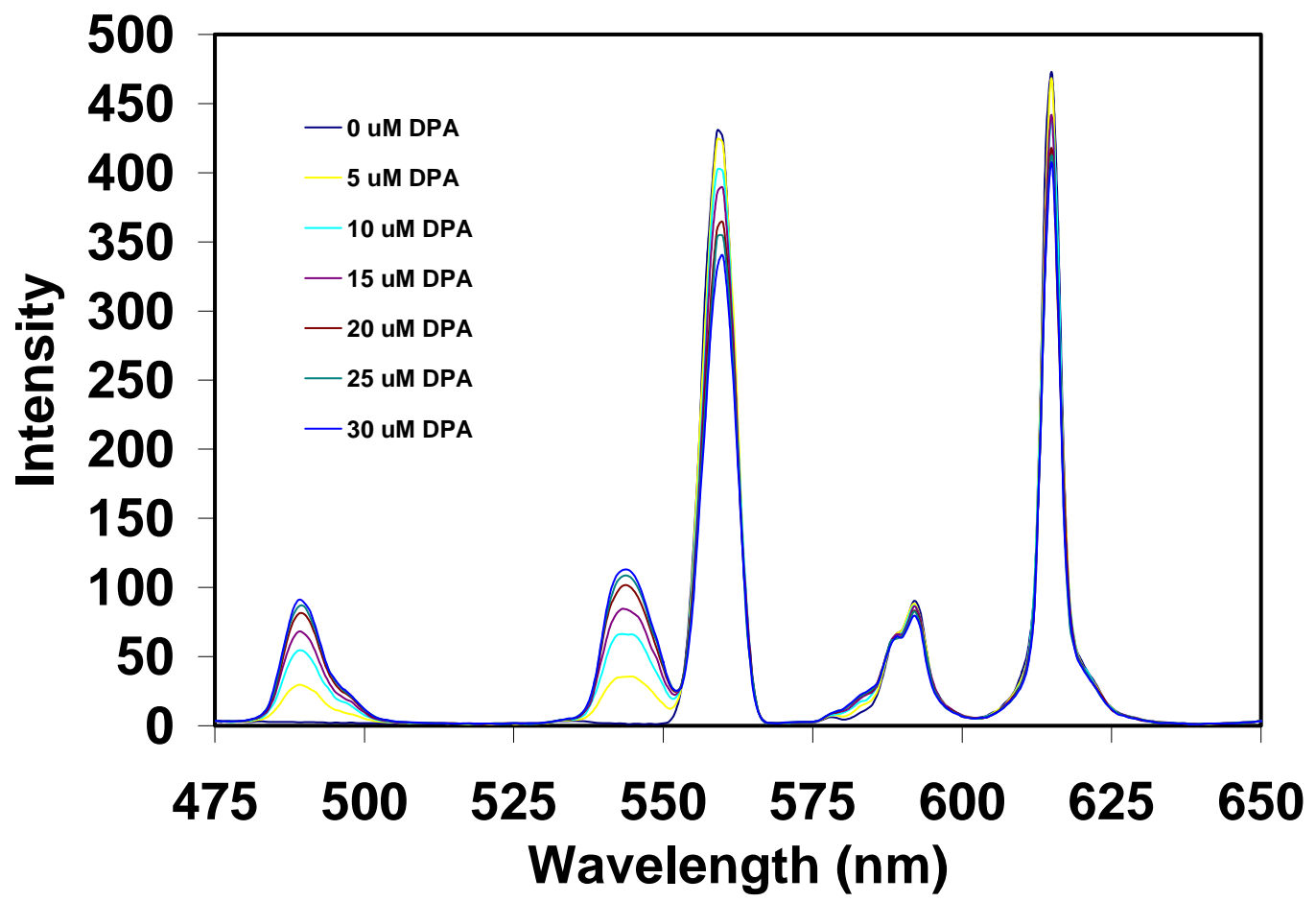

Figure S14. Luminescence vs. DPA concentration for for 3'-Tb-EDTM (with 0.05 monolayer of Tb-EDTM loading) $\left(\lambda_{\mathrm{ex}}=278 \mathrm{~nm}\right)$. 


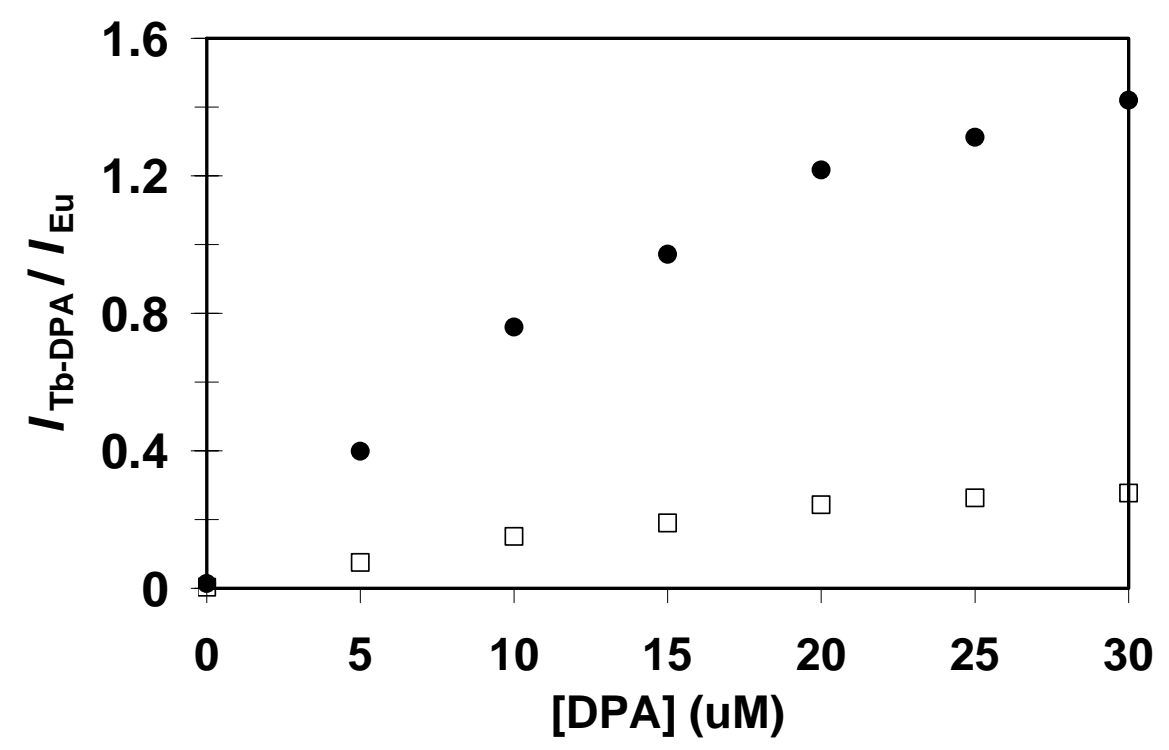

Figure S15. Ratio of Tb-DPA to Eu signal intensity vs. DPA concentration for 3'-TbEDTM (with 0.05 monolayer of Tb-EDTM loading) at low DPA concentrations (black circle $=\mathrm{Tb}-\mathrm{DPA}_{544 \mathrm{~nm}}: \mathrm{Eu}_{592 \mathrm{~nm}}$; open square $\left.=\mathrm{Tb}-\mathrm{DPA}_{544 \mathrm{~nm}}: \mathrm{Eu}_{615 \mathrm{~nm}}\right)$.

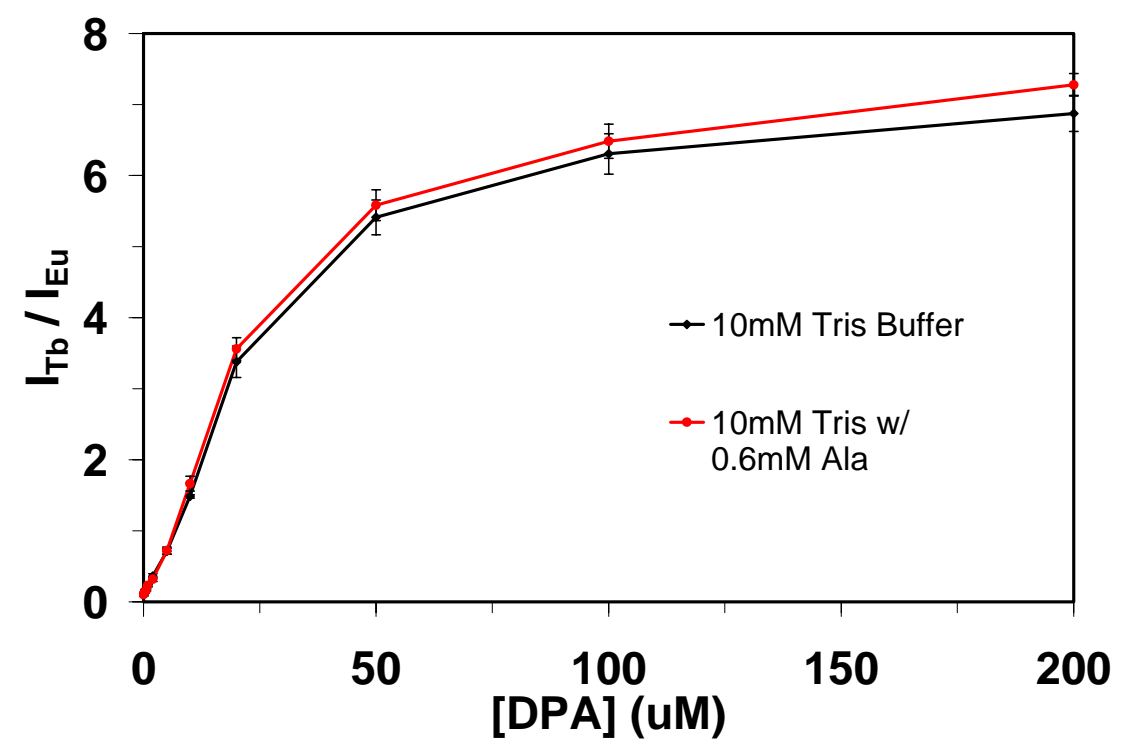

Figure S16. Dependence of the ratio of $\mathrm{Tb}(544 \mathrm{~nm})$ to $\mathrm{Eu}(592 \mathrm{~nm})$ emission intensities for $3^{\prime}$-Tb-EDTM on DPA concentration in a $10 \mathrm{mM}$ Tris buffered ethanol in water $(1: 1)$ solution (black) and in the presence of $0.6 \mathrm{mM} \mathrm{L}$-alanine (red). 


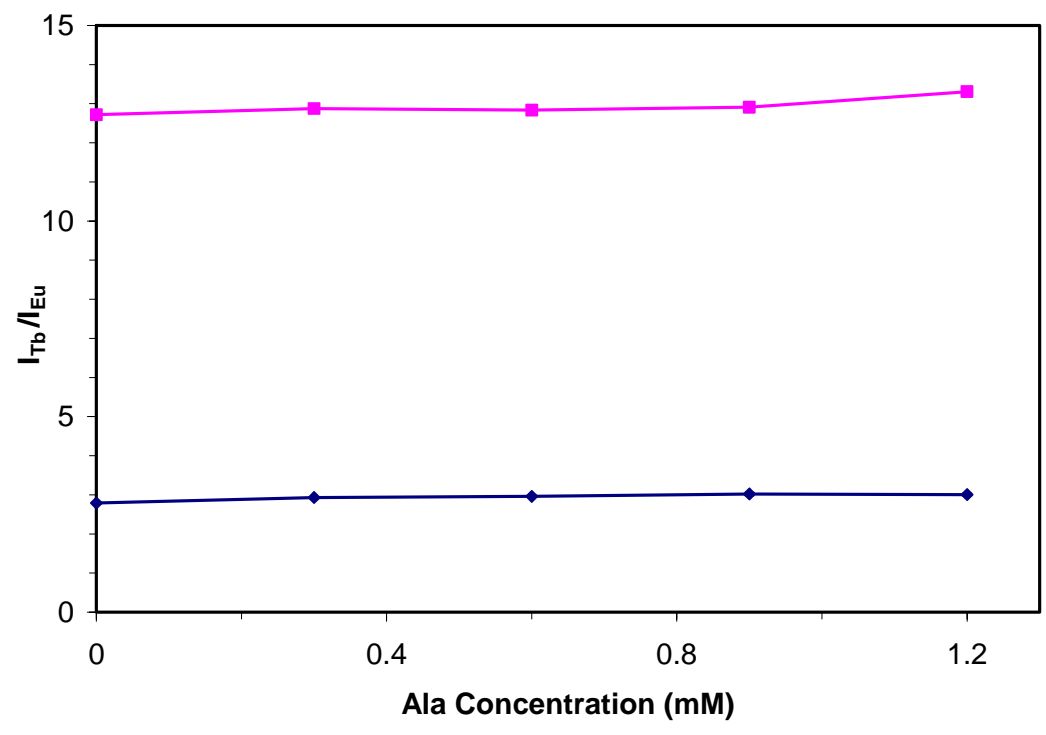

Figure S17. Ratio of $\mathrm{Tb}(544 \mathrm{~nm})$ to $\mathrm{Eu}(592 \mathrm{~nm})$ signal intensity vs. Ala concentration for $3^{\prime}$-Tb-EDTM dispersions in a $10 \mathrm{mM}$ Tris buffered ethanol in water (1:1) solution with $5 \mu \mathrm{M}$ (blue) and $150 \mu \mathrm{M}$ (pink) DPA.

\footnotetext{
${ }^{1}$ Ebright, Y.W., Chen, Y., Ludescher, R.D., and R.H.Ebright. Bioconjugate Chem. 1993, 4, 219-225.
} 